http://jmscr.igmpublication.org/home/ ISSN (e)-2347-176x ISSN (p) 2455-0450 crossref DOI: https://dx.doi.org/10.18535/jmscr/v7i7.99

Journal Of Medical Science And Clinical Research

\title{
Clinicoetiological Study of Acute Diarrhea in Children under 5 Years Age Group
}

\author{
Authors \\ Shruti Dhale ${ }^{1}$, Harshali Vankar ${ }^{2}$, Jyothi Janardhanan*3 ${ }^{3}$, Sagar Walhekar ${ }^{4}$ \\ ${ }^{1}$ M.D. Pediatrics, Associate Professor, Department of Pediatrics, Grant Govt Medical College, Mumbai \\ ${ }^{2,3}$ M.D. Pediatrics, Department of Pediatrics, Grant Govt Medical College, Mumbai \\ ${ }^{4}$ D.C.H., Department of Pediatrics, Grant Govt Medical College, Mumbai \\ *Corresponding Author \\ Jyothi Janardhanan \\ M.D. Pediatrics, Department of Pediatrics , Grant Govt Medical College, Mumbai \\ Postal Address: Kallelam house, Kozhummal, Kannur, Kerala, India
}

\begin{abstract}
Introduction: The trends of bacterial enteropathogens causing gastroenteritis keep on changing with change in standard of living and environmental hygiene. The definition of diarrhea depends on what is normal for the individual. According to K. Armon, diarrhoea is defined as a change in bowel habit for the individual child resulting in substantially more frequent and/or looser stools In developing countries. ${ }^{[1]} 50 \%$ - 60\% cases are of bacterial (Enteropathogenic Esherichia coli 25\%, Campylobacter jejuni 10\% - 18\%, Salmonella spp. and Shigella spp. 5\% each), 35\% of viral (15\% - 25\% rotavirus) origin, and in many the cause is unidentified or mixed. ${ }^{[2-5]}$
\end{abstract}

Aims and Objectives: To find out clinical features and study etiological factors of acute diarrhoea of under 5 years age group.

Methodology: A prospective study was done in a tertiary care hospital during the period of January 2017 to June 2018-12-05. All paediatric cases in the age group of below 5 years were included. A total number of 149 patients were included in the study.

Inclusion Criteria: All children presenting with acute diarrhoea in the age group of below 5 years of age admitted in paediatric ward.

Exclusion Criteria:

- Neonates are excluded

- Children who are critically ill.

- Persistent diarrhoea more than 14 days

- Malabsorbtion syndrome.

- Diarrhoea due to metal poisoning (Cadmium, Arsenic, copper, mercury,etc.).

After selection, a complete history was obtained from parents, a through general examination and systemic examination was done and findings were recorded in a specially designed proforma. Data analysis was done with use of SPSS and EXCEL Graphs and tables were prepared by MS-EXCEL. A $p$ value <0.05 was considered significant.

Results: In this study 6mo-1 year age group children were highly affected (47\%) with no sex predilection. Among the common organisms isolated 55\% were Ecoli, $4.7 \%$ were K.pneumonia, $2 \%$ were enterococcus species, $1.4 \%$ were shigella flexneri species. As per the previous records Rotavirus caused majority of the 
childhood diarrhoea. Due to lack of facilities in the institution isolation of 74 rotavirus and recognised classes of Escherichia coli (EPEC, ETEC, EHEC, EAEC and EIEC) could not be done. It was observed that out of all $50 \%$ of $S$. flexneri suffered from severe dehydration, $28.6 \%$ of all $k$. pneumonia were severily dehydrated followed by $23.2 \%$ of all ecoli. [p value $<0.0001$ (very highly significant)]. In Class V SES $44.4 \%$ suffered from severe dehydration, class IV $21.4 \%$ suffered from severe dehydration. In grade IV malnutrition $57.1 \%$ suffered from some dehydration and $42.9 \%$ suffered from severe dehydration. Fever is the predominant symptom making 53.7\% of all diarrheal patients. Association of fever presented in $100 \%$ of cases of of shigella flexneri, 66.7\% of enterococcus species presented with fever, $65.9 \%$ of ecoli followed by $57.1 \%$ of K. pneumoniae followed by commensals. [p value <0.002(highly significant)]. Hyponatremia was common finding in all children. Mean sodium of 123 was found with severe dehydration with SD 3.255, in AGE with some dehydration mean sodium was 127.77 with SD 2.860 and in AGE with no dehydration mean sodium was 130.28 and SD 2.058. This association of serum sodium and severity was significant. Uremia and metabolic acidosis were other common findings in our study. Cotrimoxazole showed highest resistance among all organisms. $100 \%$ with shigella flexneri, E.coli $63.4 \%, 57.14 \%$ K. pneumonia.

Conclusion: This study will help us in better understanding of diarrheal disease. Emphasis should be given to behavioral factors, such as improved access to sanitation, promotion of young child feeding practices, hygienic practices, and implementation of vaccines against etiologic agents, which are the burden of disease severity and also malnutrition as a whole.

Keywords: diarrhea, dehydration, shigella, E.coli.

\section{Introduction}

It is over 150 years since John Snow closed the Broad Street pump after a cholera outbreak and thereby initiated the debate on diarrheal disease risk factors and their elimination. About $80 \%$ of deaths due to diarrhoea occur in the first two years of life $\mathrm{e}^{[1,2]}$. Many times this number has long-term complications like malnutrition, growth retardation, and immune impairment. Overall, these children experience an average of 3.2 episodes of diarrhoea per child per year ${ }^{[2]}$. Although the majority of diarrhoeal episodes are not severe and may not require specific intervention, a large number are potentially fatal. ${ }^{[3]}$

In recent decades, a consensus developed that the key factors for the prevention of diarrhoea are sanitation, personal hygiene, availability of water and good quality drinking water; and that the quantity of water that people have available for hygiene is of equal or greater importance for the prevention of diarrhoea as the bacteriological water quality $^{[4]}$. Rotavirus is the single most common pathogen which causes gastroenteritis in both developed and developing countries but the trend of bacterial enteropathogens vary largely between developed and developing countries ${ }^{[5]}$.

The trends of bacterial enteropathogens causing gastroenteritis keep on changing with change in standard of living and environmental hygiene ${ }^{[5]}$. In developing countries 50\% - 60\% cases are of bacterial (Enteropathogenic Esherichia coli 25\%, Campylobacter jejuni 10\% - 18\%, Salmonella spp. And Shigella spp. 5\% each), 35\% of viral (15\% - 25\% rotavirus) origin, and in many the cause is unidentified or mixed ${ }^{[6-10]}$.

\section{Methodology}

A prospective study was done in a tertiary care hospital during the period of January 2017 to June 2018-12-05admitted in JJ Hospital, Mumbai.

All paediatric cases in the age group of below 5 years were included. A total number of 149 patients were included in the study.

\section{Inclusion Criteria}

All children presenting with acute diarrhoea in the age group of below 5 years of age admitted in paediatric ward.

\section{Exclusion Criteria}

- Neonates are excluded

- Children who are critically ill.

- Persistent diarrhoea more than 14 days

- Malabsorbtion syndrome.

- Diarrhoea due to metal poisoning (Cadmium, Arsenic, copper, mercury,etc.).

After selection, a complete history was obtained from parents, a through general examination and systemic examination was done and finding were 
recorded in a specially designed proforma. Those patients who had not given consent were excluded. Data analysis was done with use of SPSS and EXCEL Graphs and tables were prepared by MSEXCEL. A p value $<0.05$ was considered significant. Chi square test was used to establish statistical association between the different parameters

\section{Observation and Results}

The mean age group was $1.2 \pm 0.94$ years with no gender preponderance; most common age group being 6 months to 1 year.The most common clinical presentation was fever $(53.7 \%)$ followed by vomiting in $33.6 \%(\mathrm{n}=50)$, blood in stools in $14.1 \%$ $(n=21)$, increased frequency of stools, $25.5 \% \quad(n=38)$ with $<5$ episodes., Children with minimal dehydration was 65 cases $(43.6 \%)$, mild to moderate dehydration 60 cases(40.3\%).,severe dehydration 24 cases $(16.1 \%)$. It was found that all AGE, patients had hyponatremia with minimum to maximum value being 118-134 and mean of 128.9.In our study it was found that 125 cases $83.9 \%$ patients showed high urea and rest 24 cases $(16.1 \%)$ showed with normal urea levels. Serum creatinine value was high in 24 cases $16.1 \%$.

Mean sodium of 123 was found with severe dehydration with SD 3.255, in AGE with some dehydration mean sodium was 127.77 with SD 2.860 and in AGE with no dehydration mean sodium was 130.28 and SD 2.058. This association of serum sodium and severity was significant. Uremia and metabolic acidosis were other common findings in our study.

In this study, Ecoli was the most common organism isolated (Figure no 1).It was seen that different bacterial species showed resistant to different drugs whereas majority of them were resistant to Cotrimaxazole, [Ecoli 52 cases $(63.4 \%), 4$ cases $(57.14 \%)$ in K.pneumonia,2 cases(100\%) with Shigella flexneri.]

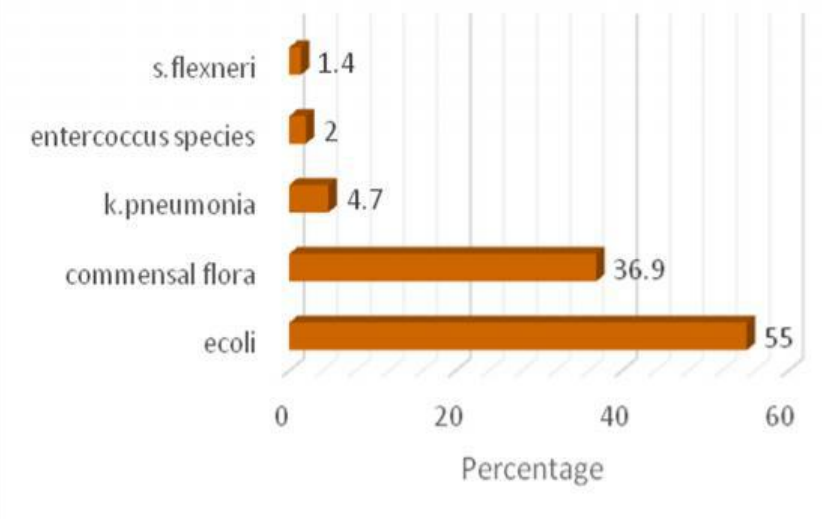

Figure No 1

It was observed that out of all $50 \%$ of S. flexneri suffered from severe dehydration, $28.6 \%$ of all $\mathrm{k}$. pneumonia were severely dehydrated followed by $23.2 \%$ of all Ecoli. [p value <0.0001(very highly significant)] (Table No 2). Association of fever presented in $100 \%$ of cases of shigella flexneri, $66.7 \%$ of enterococcus species presented with fever, $65.9 \%$ of E.coli followed by $57.1 \%$ of $\mathrm{K}$. pneumoniae followed by commensals [p value $<0.002$ (highly significant)].

\section{Table No 2}

\begin{tabular}{|c|c|c|c|c|}
\hline \multirow[b]{2}{*}{ Microorganism } & \multicolumn{3}{|c|}{ Diagnosis } & \multirow[b]{2}{*}{ Total (\%) } \\
\hline & $\begin{array}{l}\text { AGE } \\
\text { with no } \\
\text { Dehydration }\end{array}$ & $\begin{array}{l}\text { AGE with } \\
\text { some } \\
\text { dehydration }\end{array}$ & $\begin{array}{l}\text { AGE with } \\
\text { severe } \\
\text { dehydration }\end{array}$ & \\
\hline $\begin{array}{l}\text { Commensal } \\
\text { Flora }\end{array}$ & $39(70.9)$ & $14(25.5)$ & $2(3.6)$ & $\begin{array}{l}55 \\
(100.0)\end{array}$ \\
\hline E.coli & $24(29.3)$ & $39(47.6)$ & $19(23.2)$ & $\begin{array}{l}82 \\
(100.0)\end{array}$ \\
\hline $\begin{array}{l}\text { Enterococcus } \\
\text { Species }\end{array}$ & $1(33.3)$ & $2(66.7)$ & $0(0.0)$ & $3(100.0)$ \\
\hline K.pneumoniae & $1(14.3)$ & $4(57.4)$ & $2(28.6)$ & $7(100.0)$ \\
\hline S.flexneri & $0(0.0)$ & $1(50.0)$ & $1(50.0)$ & $2(100.0)$ \\
\hline Total & $65(43.6)$ & $60(40.3)$ & $24(16.1)$ & $\begin{array}{l}149 \\
(100.0)\end{array}$ \\
\hline Chi $s q=31.61$ & $d f=8$ & On001 (Ven & Highly Signif & ant) \\
\hline
\end{tabular}

Among bottle feeding infants $57.5 \%$ suffered from AGE with some dehydration, 27.5\% AGE with severe dehydration (Table No 3). 


\section{JMSCR VoI||07||Issue||07||Page 555-563||July}

Table No 3

\begin{tabular}{|c|c|c|c|c|}
\hline \multirow[b]{2}{*}{ Bottlefed } & \multicolumn{3}{|c|}{ Diagnosis } & \multirow[b]{2}{*}{ Total (\%) } \\
\hline & $\begin{array}{l}\text { AGE } \\
\text { with no } \\
\text { Dehydration }\end{array}$ & $\begin{array}{l}\text { AGE with } \\
\text { some } \\
\text { dehydration }\end{array}$ & $\begin{array}{l}\text { AGE with } \\
\text { severe } \\
\text { dehydration }\end{array}$ & \\
\hline Yes & $6(15.0 \%)$ & $23(57.5 \%)$ & $11(27.5 \%)$ & $40(100.0 \%)$ \\
\hline No & $42(54.4 \%)$ & $27(35.1 \%)$ & $8(10.4 \%)$ & $77(100.0 \%)$ \\
\hline NA & $17(53.1 \%)$ & $10(31.3 \%)$ & $5(15.6 \%)$ & $32(100.0 \%)$ \\
\hline Total & $65(43.6 \%)$ & $60(40.3 \%)$ & $24(16.1 \%)$ & $\begin{array}{l}149 \\
(100.0 \%)\end{array}$ \\
\hline Chi sc & & & $=001(\mathrm{High}$ & (Significant) \\
\hline
\end{tabular}

In Class $\mathrm{V}$ SES 44.4\%suffered from severe dehydration, class IV $21.4 \%$ suffered from severe dehydration. In grade IV malnutrition $57.1 \%$ suffered from some dehydration and $42.9 \%$ suffered from severe dehydration (Table No 4).

\section{Table No 4}

\begin{tabular}{|c|c|c|c|c|}
\hline \multirow[b]{2}{*}{$\begin{array}{l}\text { Nutrition } \\
\text { Status }\end{array}$} & \multicolumn{3}{|c|}{ Diagnosis } & \multirow[b]{2}{*}{ Total (\%) } \\
\hline & $\begin{array}{l}\text { AGE } \\
\text { with no } \\
\text { Dehydration }\end{array}$ & $\begin{array}{l}\text { AGE with } \\
\text { some } \\
\text { dehydration }\end{array}$ & $\begin{array}{l}\text { AGE with } \\
\text { severe } \\
\text { dehydration }\end{array}$ & \\
\hline Grade I & $9(52.9)$ & $8(47.1)$ & $0(0.0)$ & $17(100.0)$ \\
\hline Grade II & $2(7.1)$ & $14(50.0)$ & $12(42.9)$ & $28(100.0)$ \\
\hline Grade III & $4(25.0)$ & $8(50.0)$ & $4(25.0)$ & $16(100.0)$ \\
\hline Grade IV & $0(0.0)$ & $4(57.1)$ & $3(42.9)$ & $7(100.0)$ \\
\hline Normal & $50(61.7)$ & $20(32.1)$ & $5(6.2)$ & $81(100.0)$ \\
\hline Total & $65(43.6)$ & $60(40.3)$ & $24(16.1)$ & $149(100.0)$ \\
\hline
\end{tabular}

\section{Discussion}

It is widely recognized that diarrhea is a major cause of morbidity and mortality among children, especially children in developing countries.

Low socio-economic status, poor environmental sanitation and low hygienic practices pose a serious threat to people's health, especially children's health. Risk factors for diarrhea vary with the child's age, the pathogens involved, and the local environment.

We observed that cases were mostly children less than 12 months of age, 16(10.7\%) cases less than 6 months of age excluding the neonates, in 6 months1 year of age 70 cases (47\%) making total of $57.7 \%$. According to Molbak $\mathrm{K}$ et $\mathrm{al}^{[11]}$ and Woldemicael $\mathrm{G}^{[12]}$, the rates of diarrhea were highest for children 6-11 months of age, remained at a high level among the 1-5 year old children and decreased when children got older. The high incidence of diarrheal disease in Khanduja et $\mathrm{al}^{[13]}$ and Sood $S^{[14]}$ suggested that the high incidence of diarrheal disease in the first 2 years of life is probably related to faulty weaning, unhygienic handling and storage of milk and food, higher incidence of parental infection, malnutrition, development of mouthing habits at this age. A decrease in number of cases among older children might be resulted from a fact that the immune system in older children got stronger in resisting against agents.

In our results defining socioeconomic status according to modified kuppuswamy scale, diarrhea in class I 5 cases $(3.4 \%)$, class II $48(32.2 \%)$, class III 59(39.6\%), class IV 28(18.8\%), class V 9 cases $(6 \%)$. Class V SES $44.4 \%$ suffered from severe dehydration, class IV $21.4 \%$ suffered from severe dehydration, class III $18.6 \%$ suffered from severe dehydration $20 \%$ from class I followed by class II $4.2 \% .60 .7 \%$ with class IV suffered from some dehydration, $42.4 \%$ class III suffered from some dehydration followed by $31.3 \%$ by class II, class V $22.2 \%, 20 \%$ by class I.In our study correlation between severity of diarrhea and lower socioeconomic status was statistically significant. [Chi sq $=24.602, \mathrm{df}=8, \mathrm{p}=0.002$ (Highly Significant)]. As per Gerald T. Keusch et $\mathrm{al}^{[15]}$, the frequency and severity of diarrhea is aggravatedby lack of access to sufficient clean water and sanitary disposal of human waste, inadequate feeding practices and hand washing, poor housing conditions and lack of access to adequate and affordable health care. A literate woman is able to take decisions regarding the severity of disease that her child might be suffering with and is also able to recognize the health care facilities that are available close to her house for her children is responsible for severity of illness in low socioeconomic class. 
According to Rasania SK et al ${ }^{[16]}$ studies done in India and abroad have also reported varied prevalence of diarrhea which might be due to difference in study methodology, nature of population, geographic, seasonal variation and socioeconomic condition of the community selected. In Indian slums nearly 100,000 babies die every year before their fifth birthday (NFHS-3 India, 2005-06), as a result of dehydration, weakened immunity or malnutrition associated with diarrhea ${ }^{[17]}$ In present study it was found that $55(36.9 \%)$ were commensals, $82(55 \%)$ were Ecoli, $7(4.7 \%)$ were K.pneumonia, 3(2\%) were enterococcus species, 2(1.4\%) were shigella flexneri species. This pattern was similar to other studies done in India by workers like Joshi et $\mathrm{al}^{[18]}$.

Out of all diarrheal patients $43.6 \%$ suffered from no dehydration, $40.3 \%$ suffered some dehydration, $16.1 \%$ pts had severe dehydration. Study by Haricharan. K et $\mathrm{al}^{[19]}$, some dehydration was present in $80 \%$ of thecases and $14 \%$ had severe dehydration and $6 \%$ had no dehydration. Monika pathania et al ${ }^{[20]}$, out of all $67.1 \%$ children presented with some dehydration followed by no dehydration (23.5\%) and severe dehydration (9.6\%). Among all E.coli in stool culture $29.3 \%$ suffered from no dehydration, $47.6 \%$ from some dehydration, $23.2 \%$ from severe dehydration. Of all Shigella in stool culture 50\% presented with some dehydration and $50 \%$ with severe dehydration. Of all K. pneumonia $57.4 \%$ presented with some dehydration and $28.6 \%$ presented with severe dehydration, rest with no dehydration. In Enteroccocus species $66.7 \%$ presented with some dehydration and $33.3 \%$ with no dehydration, among the commensals $70.6 \%$ with no dehydration.

This correlation between organism and severity was statistically significant. $P$ value $<0.0001$. In study by Monika et al $2014^{[20]}$, out of 124 patients of Escherichia coli 80 patients $(64.5 \%)$ presented with some dehydration and rest with no dehydration.

History of bottle feeding in infants was enquired it was found that $26.3 \%$ were taking bottle feeding $51.3 \%$ of infants were not bottle feed. Relation of bottle feeding with severity of diagnosis in infants was found that $6(15 \%)$ had suffered from AGE with no dehydration, $23(57.5 \%)$ from AGE with some dehydration, 11 (27.5\%) from AGE with severe dehydration. Infants who were not bottle feed 42 (54.4\%) had no dehydration, 27 (35.1\%) had some dehydration, $8(10.4 \%)$ had severe dehydration. This correlation was statistically significant Chi sq $=19.184, \mathrm{df}=4, \mathrm{p}=001$ (Highly Significant). Bottle fed (BF) infants face an increased risk of gastroenteritis and diarrhea. Infants who are bottle fed are 2.8 times more likely to develop gastrointestinal $^{[21]}$. A study by Hussain $\mathrm{Z}$ Khan et $\mathrm{al}^{[22]}$, diarrhea was more common in BF infants than in exclusively breastfed (EBF) infants as it shows that in $\mathrm{BF}$ infants $26 \%$ were suffering from diarrhea whereas $24 \% \mathrm{EBF}$ infants were suffering.

In present study it was found that patients with grade 1 malnutriton $9(52.9 \%)$ suffered from no dehydration and 8(47.1\%) suffered some dehydration. Patients with grade II malnutrition $14(50 \%)$ had some dehydration, 12 (42.9\%)had severe dehydration. Among grade III malnutrition 4 $(25.0 \%)$ suffered from no dehydration,8 $(50.0 \%)$ suffered from some dehydration, 4 (25.0\%) suffered from severe dehydration. In grade IV malnutrition none had no dehydration, $4(57.1 \%)$ had some dehydration, $3(42.9 \%)$ had severe dehydration. This relationship between severity and malnutrition was found to be very highly significant with $p$ value 0.0001 Chi sq $=46.394 \mathrm{df}=8$. Farzana et $\mathrm{al}^{[23]}$, malnourished children were more likely to present with visible or reported blood in their stool $(\mathrm{P}<$ $0.001)$, suffer from some or severe dehydration $(\mathrm{P}=$ $0.005)$, and receive intravenous fluid $(\mathrm{P}=0.002)$ compared with well-nourished children. Among Minimal to severe dehydration children, 35\% were malnourished compared with $24 \%$ of Minimal dehydration children $(\mathrm{P}<0.001)$.

Monika Pathania et al $\mathrm{a}^{[20]}$, fever was found to be a predominant clinical feature present in $89.6 \%$ of patients of diarrhea, Vomiting $61.8 \%$,increased frequency of stools $52.5 \%<5, \quad 38.2 \% \quad 5-10$, $8.2 \%>10$.Fever was predominant symptom $(n=80)$ $53.7 \%$ in all diarrheal patients. All100\% patients who had diarrhoea due to shigella flexneri suffered 
from fever, patients with enterococcus $66.7 \%$ had fever, patients with diarrhea due to ecoli65.9\% had fever followed by diarrhea due to $\mathrm{K}$. pneumonia $57.1 \%$ followed by commensals $32.7 \%$.In this study association of fever with microorganisms was highly significant with chi square $=16.262 \mathrm{df}=4 \mathrm{p}=$ 0.002 (Highly Significant).From the above finding it can be described that fever is a common clinical feature in diarrhoea with Shigella flexnri occupying the majority with all the cases presenting with fever. Monika Pathania et $\mathrm{al}^{[20]}$ found that all $100 \%$ patients who had diarrhea due to Salmonella suffered from fever, followed by patients of diarrhoea due to Escherichia coli $(93.5 \%)$, Shigella (91.1\%), Klebsiella (72.7\%) and Campylobacter $(52.9 \%)$.

Study on electrolyte disturbances showed that, all patients suffered from hyponatremia. A study by Samadi et $\mathrm{al}^{[24]}$. included children admitted with diarrhea. This showed that hyponatremia and hypernatremia were present in $20.8 \%$ and $6.4 \%$ cases, respectively.

Different studies have shown different prevalence's of hyponatremia and hypernatremia among children with dehydration. Chouchane et al ${ }^{[25]}$ hypernatremia was present in $11.51 \%$ cases of all kinds of dehydration. The study by Shah et al ${ }^{[26]}$ showed that $56 \%$ of cases admitted with diarrhea and dehydration had hyponatremia, while hypernatremia was present in $10 \%$ cases. Different factors can alter the prevalence of electrolyte disorders among children with diarrhea. Malnutrition is one of these factors. Children with some dehydration mean sodium was found to be 127.77. Children with severe dehydration mean sodium was found to be123.62. This correlation between serum sodium and severity was very highly significant. Factor that can alter the amount of electrolyte loss in stools is the causative pathogen. Diarrhea due to different pathogens can lead to significantly different amount of electrolyte loss in the stool. It can also increase significantly because of electrolyte transport into fecal water due to exogenous substances and toxins, e.g. cholera toxin. Patients with high urea were $83.9 \%$ with min to max value being 18-31, andmean value of 24.05 SD 4.15.serum creatinine value was high in 16.1. A study by Mirza Sultan Ahmad et $\mathrm{al}^{[27]}$ found that Urea level was high in88 (84.6\%) patients. Creatinine level was high in 36 $(34.6 \%)$.high urea is due to volume depletion and decreased blood supply to kidneys and increase in ADH levels. In acid base disturbances it was found that $22.1 \%$ diarrheal patients had metabolic acidosis in that $32.9 \%$ had partially compensated metabolic acidosis. A study by Shah et al ${ }^{[26]}$ it was found that $94 \%$ had metabolic acidosis and $6 \%$ with metabolic alkalosis in diarrheal patients. Hypokalemia, hyponatremia and metabolic acidosis are the common electrolyte and acid base abnormalities in children with diarrhea and dehydration and often responsible for mortality.

The pattern of antibiotic susceptibility of various bacterial pathogens matches to greater extent to work done by Daniel R., and Diniz-Santos, et al ${ }^{[28]}$. High resistance to Co-trimoxazole among all pathogens can be attributed to its injudicious use among the population because of its wide antimicrobial spectrum most likely to be used for various infections. E. coli isolates were found to have a high rate of resistance to first line Cotrimoxazole, ampicillin and ciprofloxacin, in third genereation cephalosporins ceftazidime and ceftriaxone resistance was seen. This can be explained as E. colibeing so common agent of diarrhoea, its strains are most mostly exposed to different antibiotics injudiciously. Monika Pathania et $\mathrm{al}^{[20]}$ found that $\mathrm{E}$. coli isolates were found to have a highrate of resistance to ampicillin, ampicillin + sulbactam and Co-trimoxazole. The knowledge of resistance pattern of common etiological agents in local area can help practitioners to choose an adequate antimicrobial drug to start empirical therapy to prevent the illness.

\section{Conclusion}

- The incidence was more in the age group of 6 months to 1 year of age.

- Bottle feeding, Low socioeconomic class and malnutrition were associated with severity of AGE in children. 
- Most common organism isolated was Ecoli followed by commensals, K.p neumonia, enterococcus species, shigella fexneri.

- Children with acute diarrhea should be monitored for the development of severe dehydration, decreased urine output and electrolyte derangement especially hyponatremia and acid base disturbances.

- Emphasis should be given to behavioral factors, such as improved access to sanitation, promotion of young child feeding practices, hygienic practices, and implementation of vaccines against etiologic agents, which are the burden of disease severity and also malnutrition as a whole.

\section{Recommendations}

- The incidence of allergies, infections (cold $\&$ flu) and diarrhea is more prevalent in bottle-fed infants as compared to exclusively breast-fed infants. But there is a need to assess in future researches about how to reduce the prevalence of allergies and diarrhea in bottle-fed.

- Building toilets and providing safe drinking water at the household level will reduce the burden of diseases in the community.

- Interventions through effective health education of the community regarding appropriate complimentary feeding and immunization practices may reduce the burden of diarrhoea among these children.

- Efforts to further increase rotavirus vaccine coverage rates to better protect all children against rotavirus disease should be made as it is the common cause for diarrheal illness in infants and young.

- Proper use of ORS, according to WHO recommendations, should be promoted to prevent electrolyte imbalance.

- The above activities along with IEC for safe drinking water, excreta disposal and personal hygiene needs to be done regularly and continuously so that morbidity and mortality due to diarrhoeal disease are effectively prevented slums.

- Encourage mothers to wash their hands with soap before feeding children or after going to toilet.

- Numerous health organizations worldwide donate large amounts of antibiotics, the composition of such donations should be based on current knowledge of the common local pathogenic bacteria and their susceptibility patterns.

\section{Limitations}

Recognised classes of Escherichia coli (EPEC, ETEC, EHEC, EAEC and EIEC) and Rotavirus by (RT-PCR) were not isolated due to lack of facility in the institution.

\section{Bibliography}

1. Urio EM, Collison EK, Gashe BA, Sebunya TK and Mpuchane S. Shigella and Salmonella strains isolated from children under 5 years in Gaborone, Botswana, and their antibiotic susceptibility patterns. Trop Med Int Health 2001; 6(1): 55-9. 2.

2. Kosek M, Bern C, Guerrant RL. The global burden of diarrhoeal disease, asestimated from studies published between 1992 and 2000. Bull World HealthOrgan 2003; 81 (3): 197-2043.

3. Vesikari T and Torun B. Diarrheal Diseases. In: Kari SL, Staffan B, MakelPH, Miikka P, editors. Health and Disease in developing countries. Macmillan Education Ltd. London and Oxford, 1994.p.136-46.

4. Jensen PK, Jayasinghe G, van der Hoek W, Cairncross S, Dalsgaard A. Isthere an association between bacteriological drinking water quality and childhood diarrhea in developing countries? Trop Med Int Health; 2004; 9(11): 1210-15.

5. Lee WS, Puthucheary SD. Bacterial enteropathogens isolated in childhood 
diarrhoea - the changing trends. Med J Malaysia. 2002;57:1.

6. A. C. Cheng, J. R. McDonald and N. M. Thielman, "Infectious Diarrhea inDeveloped and Developing Countries," Journal of Clinical Gastroenterology, Vol. 39, No. 9, 2005, pp. 757-773E.

7. J. Elliott, "Acute Gastroenteritis in Children," British Medical Journal (BMJ),Vol. 334, No. 7583, 2007, pp. 35-40. doi:10.1136/bmj.39036.406169.80

8. M. E. Wilson, "Diarrhea in Non travelers: Risk and Etiology," Clinical Infectious Diseases, Vol. 41, No. 8, 2005 pp. S541S560.doi:10.1086/43294980

9. N. A. Cunliffe, P. E. Kilgore, J. S. Breasee, et al., "Epidemiology of Rotavirus Diarrhea in Africa: A Review to Assess the Need for Rotavirus Immunization," Bulletin of the World Health Organization, Vol. 76, No. 5,1998, pp. 525-537.

10. M. Naghipour, T. Nakgomi and O. Nakagomi, "Issues with Reducing the Rotavirus Associated Mortality by Vaccination in Developing Countries," Vaccine, Vol.26,No.26,2008, pp.3236-3241. doi:10.1016/ j.vaccine. 2008.04.004.

11. Molbak K. The epidemiology of diarrheal diseases in early childhood: Areview of community studies in Guinea-Bissau. University of Copenhaghen, 2000

12. Woldemicael G. Diarrheal morbidity among children in Eritrea: environmentaland socioeconomic determinants. J Health Popul Nutr; 2001; 19 (2): 83-90.

13. Khanduja PC, Bhargava SK: Etiological aspects of diarrhoea in infants and children under 5yrs.Indian J pediatrics 1969; 36: 237.

14. Sood S. Etiology of diarrhoea in infancy. Indian J. Ch.Hlth, 1963; 12: 727.

15. Gerald T. Keusch, O F and Alok B (2001). Disease Control Priorities in Developing Countries, 371-388.

16. Rasania SK, Singh D, Pathi S, Singh S. Knowledge and Attitude of mothers about
ORS in few urban slum of Delhi. Health and Population -Perspectives and issues 28(2): 100-107,2005.

17. Diarrhoea: Why children are still dying and what can be done' UNICEF/ WHO joint report on preventing and treating the second leading killer of children, http://www.unicef.org/health/index_51412.h tml).

18. Joshi CK, Bharadwaj AK, Vyas BL .study of bacterial infantile diarrhoea. Indian $\mathrm{J}$ Pediat.1980; 47:307-310.

19. Haricharan. K, Shrinivasa. B. M, Vatsala Kumari Clinical and bacteriological Study Of Acute Diarrhoea In Children, Journal of Evolution of Medical and Dental Sciences/ Volume 2/ Issue 23/June 10, 2013 Page 4231.

20. Monika Pathania et al., Clinical Study of Acute Childhood Diarrhea Causedby Bacterial Enteropathogens journal of clinical and diagonostic research2015 May vol8(5).

21. World Health organisation (1991) indicators for assessing infant and young child feeding practices. WHO Press Washington D.C.WHO Publications.

22. Hussain Z, Khan N (2017) Assessment of the Nutritional Status of Bottle-Fed Infants and the Prevalence of Infections, Allergy and Diarrhea among Bottle Fed Infants and Its Comparison with Exclusively Breast Fed Infants Aged 0-6 Months. J Pediatr Neonatal Care 6(4): 00249 DOI:10.15406/jpnc.2017.06.00249.

23. Farzanaferdous Severity of Diarrhea and Malnutrition among Under Five-Year-Old Children in Rural Bangladesh the American Society of Tropical Medicine and Hygiene 2013.

24. Samadi AR, Wahed MA, Islam MR, Ahmed SM. Consequences of hyponatraemia and hypernatraemia in children with acute diarrhoea in Bangladesh. Br Med J (Clin Res Ed)1983; 286:671-3. 
25. Chouchane S, Fehri H, Chouchane C, Merchaoui Z, Seket B, Haddad S, etal. Hypernatremic dehydration in children: retrospective study of 105 cases.Arch Pediatr 2005; 12:1697-702.

26. Shah GS, Das BK, Kumar S, Singh MK, Bhandari GP. Acid base and electrolyte disturbance in diarrhoea. Kathmandu Univ Med J (KUMJ) 2007;5:60-2.

27. Mirza Sultan Ahmad Prevalence of Electrolyte Disorders Among Cases of Diarrhea with Severe Dehydration and Correlation of Electrolyte Levels with Age of the Patients Journal of the College of Physicians and Surgeons Pakistan 2016, Vol. 26(5): 394-398.

28. Daniel R. Diniz-Santos, et al. Epidemiological and microbiological aspects of acute bacterial diarrhoea in children from Salvador, Bahia, Brazil. Braz JInfect Dis vol.9 no.1 Salvador. 2005. 